Endocrinol. Japon., Vol. 3, No.. 2 (1956)

\title{
MODE OF OCGURRENCE OF STEROID HORMONES IN THE BLOOD SERUM
}

\author{
HISASHI OKADA \\ Endocrinological Laboratories, School of Medicine, \\ Gunma University
}

Since Zaffaroni (1949, 1950, 1951) succeeded in separating free steroids with the use of paper chromatography, attempts have been done to gain useful technics for the development of steroids on the paper. Neher and Wettstein (195la,b) and Bush (1952) introduced a technic, in which fluorescent reaction of steroids was observed either in saturated chloroform solution with antimony trichloride, or in phosphoric acid or in sodium hydroxide solution. Durrum (1950) reported the method of paper electrophoresis (P. E.) which could separate various fractions of serum protein. With this method, Voigt and Beckmann (1953, 1954) separated esterified desoxycorticosterone and dehydroisoandrosterone by means of P.E., and McKinely (1955) succeeded in separating ketosteroids in their hydrazone compounds. Such are only a few examples of recent attempts of separation of steroids by P. E., but it might be pointed out that all of such studies have been concerned with free states of steroids employed, not dealing with conjugated forms with protein of any kind of steroid. According to the determination of protein solubilities (Eik-Nes, 1954), almost all the steroids appear circulating in conjugated forms with one or some of albumin, $\alpha$-globulin or $\beta$-globulin in the blood.

The author isolated the substances of fraction IV-1 by the technic of Cohn (1946), and approached $\alpha$-globulin, $\alpha$-lipoprotein and a little amount of $\beta$-lipoprotein with various staining methods and fluorescent reactions on strips treated by P. E.

\section{MATERIALS AND METHODS}

Sample 1. Normal ox serum: The normal ox serum was separated by centrifugation of the blood collected from the carotid artery of adult animals killed by blow, and approximately $500 \mathrm{ml}$ of the serum was mixed with $50 \mathrm{ml}$ of $4 \%$ sodium citrate solution. Cohn's fraction IV-1 isolated from the serum was employed in the following treatment as samples.

Sample 2. Normal rabbit serum (juvenile males; body weight, $2.5-3.0 \mathrm{~kg}$ ) : After serum was separated from $10 \mathrm{ml}$ of the blood collected from the carotid vein, the sample was extracted by Cohn's method.

Sample 3. Prior to collection of blood sample from the carotid vein, $1 \mathrm{~g}$ of sample 1 (completely dissolved in $10 \mathrm{ml}$ of physiological saline) was injected into the muscle of the rabbits (normal juvenile males), and the sample employed in this investigation was isolated from the blood taken at 60 mins. and 120 mins. respectively following the injection.

Received for publication June 28, 1956. 
Sample 4. After $10 \mathrm{mg}$ of free testosterone* (dissolved in $5 \mathrm{ml}$ of mixture of absolute ethanol and $20 \%$ glucose solution) was injected into the auricural vein of the normal juvenile male rabbit, two samples of Cohn's fraction IV-1 isolated at 30 mins. and 60 mins. respectively after the injection were processed from the serum of the same rabbit.

Sample 5. The sample employed in this attempt was isolated at 30 mins. and 60 mins. respectively following injection of $10 \mathrm{mg}$ of $\mathrm{DOCA}^{*}$ after similar method used for the extraction of sample 4.

Sample 6. This sample was extracted from the rabbit serum at 30 mins. and 60 mins. respectively after injection of $10 \mathrm{i}$. u. of ACTH (dissolved in $5 \mathrm{ml}$ physiological saline).

Sample 7. Mixture of $0.1 \mathrm{~g}$ of sample 1 with $50 \mu \mathrm{g}$ of crystallized testosterone completely dissolved in $1 \mathrm{ml}$ of $15 \%$ propyleneglycol was run on P. E.

Sample 8. Mixture of $0.1 \mathrm{~g}$ of sample 1 with $50 \mu \mathrm{g}$ of DOGA was applied to P.E. in the same way as in the preceding case.

All of the samples were applied to P.E. In addition, the sample 1,2,3 and 4 were examined by paper chromatography, and furthermore, sample 1 was fractionated by electrophoresis. To develop all components moved on filter paper strips, following color reagents were employed: bromophenol blue (Griffiths, 1953), Amidoschwalz 10 B (Grasman, 1951), Sudan Black, m-dinitrobenzene, potassium triiodide (Bush, 1950), triphenyltetrazolium chloride (Dangerfield, 1955), silver nitrate (Burton, 1951), dithizone (Isobe, 1955), $\alpha$-nitroso- $\beta$-naphthol, phosphoric acid (Neher, 1951) and antimony trichloride (Neher, 1951).

Each sample applied to P. E. was dissolved in phosphate buffer ( $\mathrm{pH} 7.0)$ up to the amount of $10 \%$ by the reading of protein refractometer, and $0.1 \mathrm{ml}$ of the sample was used to determine the distribution of steroids and proteins. For P.E., phosphate buffer ( $\mathrm{pH} 8.0, \mu=0.1$ ) was employed, and electrophoresis was run at 100 to 200 volts and $0.5 \mathrm{~mA}$ per $1 \mathrm{~cm}$ strips $(1 \times 25 \mathrm{~cm})$ for periods ranging from 11 to $16 \mathrm{hrs}$. at 0 to $3^{\circ} \mathrm{C}$. Filter paper strips used were of the label of Toyo Roshi No. 51 .

In the experiments with paper partition chromatography, samples were developed after the method of one-dimensional ascending pattern. As solvents, use was made of $n$-butanol saturated with water system as the polar solvent and ligroin-methanol-water mixtures system $(5: 4: 1)$ as the non-polar solvent.

$0.1 \mathrm{~g}$ albumin obtained from the blood of ox was dissolved in propyleneglycol solution with $50 \mu \mathrm{g}$ of each crystallized ethinyl estradiol, estriol, progesterone, testosterone, dehydroisoandrosterone, cortisone and hydrocortisone and after $0.1 \mathrm{ml}$ of each mixture had been treated by P. E., mobilities of each steroid run on strips being optically determined by the method of fluorescent reaction. In this fluorescent investigation hydrogen lamp was used as the light source, and an optical filter $(\lambda \max .=365.5 \mathrm{~m} \mu)$ was employed.

\section{RESULTS}

Electrophoretic analysis of ox sample, using the Cohn's technic was shown by Fig. 1. (Present isolation failed to obtain pure $\alpha$-globulin, which contained in Cohn's IV-1 fraction, after single treatment by Cohn's method, slight amounts of albumin and $\beta$-globulin being co-existing with $\alpha$-globulin.)

To examine each protein spot on strips after P.E., BPB and Amidoschwalz 10B, Sudan Black for lipid and m-dinitrobenzene (m-DNB), silver nitrate, TPTZ, dithizone, ferric-ferrocyanide, $\alpha$-nitroso- $\beta$-naphthol, potassium triiodide, phosphoric

* These samples were manufactured by Teikoku Hormone MFG. Co., LTD. and kindly placed at the author's disposal. 
acid and antimony trichloride were utilized as staining reagents of steroids. To gain quantitative data on the intensity of light absorption of substances stained with above mentioned reagents after electrophoretic analysis, the Coleman's nepho-colorimeter was employed. And curves of transmittancy reading for sample were used for calibration. Phosphoric acid and antimony trichloride could not be determined by colorimetry on account of that strips became fragile by heating. To observe colorimetrically distribution of the substances containing the radical of methyleneketone on the strip, the reaction of $\mathrm{m}-\mathrm{DNB}$ was performed as follows; equal volumes of redistilled absolute ethanol containing $0.2 \% \mathrm{~m}-\mathrm{DND}$ and $6 \mathrm{~N}$ potassium hydroxide solution in absolute ethanol were mixed prior to the investigation. As soon as strips were

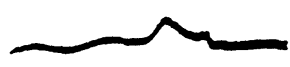
sprayed with this solution, they were dried at $110^{\circ} \mathrm{C}$ for 90 secs. and measured within 5 mins. by the nepho-colorimeter. In cases to determine m-DNB-positive band on strip by spectrocolorimetric method, it was most convenient to employ No. 4010 Corning filter with maximal absorption at $525 \mathrm{~m} \mu$. In the absorption curve of the strips reacted with $\mathrm{m}-\mathrm{DNB}$, generally five peaks were observed (Fig. 2 ). One corresponded to the albumin fraction (Ip), one to $\alpha$-globulin fraction (IIp), and one to $\beta$-globulin fraction (IIIp) in the serum protein. One peak appeared adjacent to just negative side of IIIp part (IVp) and another at original part $(\mathrm{Vp})$. IVp and $\mathrm{Vp}$ were characteristic of $\mathrm{m}-\mathrm{DNB}$ treatment, which disappeared in BPB staining. But in the case of the ox serum, as an exceptional

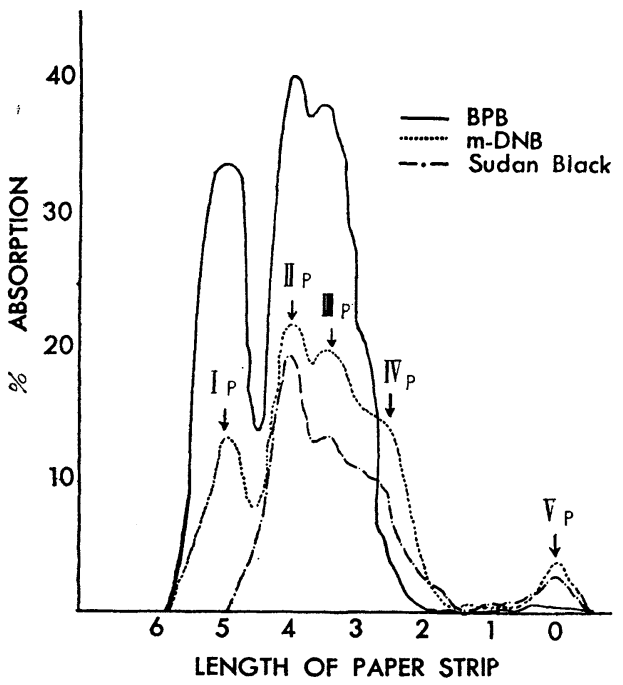

Fig. 2. Result of Paper Electrophoresis of Normal Rabbit Sample case, Vp substance was stained not only with $\mathrm{m}-\mathrm{DNB}$ and Sudan Black, but with BPB.

Experiment (1) sample 1: In this experiment the degree of absorbance IVp was $8 \mathrm{~A} \% *$, one fifth of that of IIp level, and each peak elevated proportionaly with the increase of concentration of the sample.

Experiment (2) sample 2 (Fig. 2): In the present Cohn's fraction albumin was contained at the $\mathrm{A} / \mathrm{G}$ ratio 30.6 to 68.8. On m-DNB reactions, absorbance of IVp was $13 \mathrm{~A} \%$, being comparable to that of $\mathrm{Ip}$, and $\mathrm{Vp}$ was $3 \mathrm{~A} \%$. Also, on the ultraviolet test of phosphoric acid or antimony trichloride, 3 to 5 fluorescent bands were observed. One corresponded to the part of albumin, one

\footnotetext{
* Reading value of light absorbance- $\%$ absorption.
} 


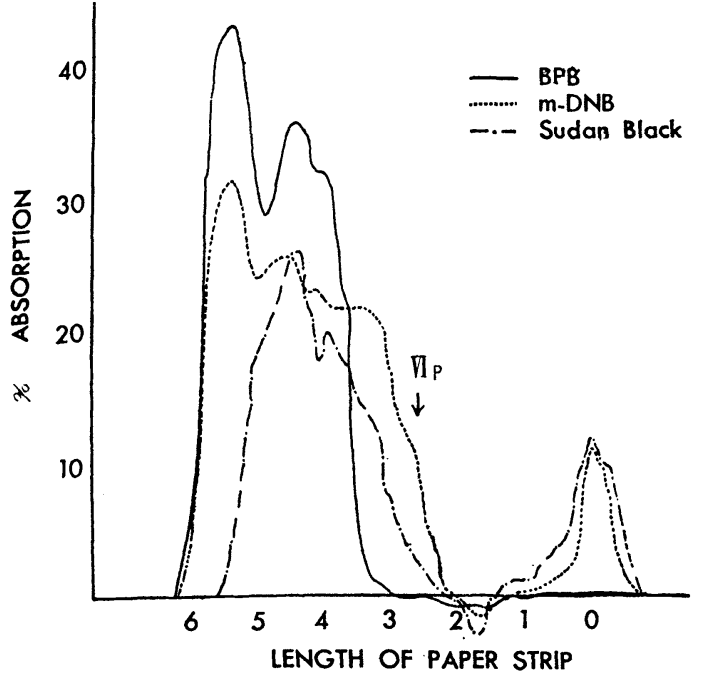

Fig. 3. Result of Paper Electrophoresis of Rabbit Sample Injected Ox Sample (120 Mins. after the Injection)

to $\alpha$-globulin and one to $\beta$-globulin fluoresced the white blue color (occasionally the latter two have not been completely separated from each other). One part corresponding to IVp which fluoresced white yellow and the other part corresponding to $\mathrm{Vp}$ fluorescing light pink under ultraviolet irradiation.

Assuming that the absorbance of IVp in this experiment was corresponding to free testosterone, calculation was made which showed that amounts of free testosterone corresponding to the level of $13 \mathrm{~A} \%$ should be be about $2 \mu \mathrm{g}$ in $1 \mathrm{ml}$ of ethanol as the result of the spot test. $0.1 \mathrm{ml}$ of sample 2 dissolved in phosphate buffer solution at the volume ratio of $10 \%$ was used for P.E., if all values of IVp were originated from testosterone, amounts of steroid hormone contained in IVp should be $10 \mu \mathrm{g} / \mathrm{g}$ in the sample and $5 \mu \mathrm{g} / 100 \mathrm{ml}$ in the rabbit serum. The values of $3 \mathrm{~A} \%$ of $\mathrm{Vp}$ of this experiment corresponded to the absorbance of DOCA $5 \mu \mathrm{g}$ dissolved in $1 \mathrm{ml}$ of ethanol as the result of spot tests on paper. Therefore, according to such a conversion of the values of $3 \mathrm{~A} \%$ at $\mathrm{Vp}$ into volume of free DOCA having the same absorbance, DOCA of $250 \mu \mathrm{g} / \mathrm{g}$ in the sample isolated from $200 \mathrm{ml}$ of the rabbit serum, and $125 \mu \mathrm{g} / 100$ $\mathrm{ml}$ in the serum should be contained. According to the technic of Heard, Sobel and Venning (1946), this $125 \mu \mathrm{g}$ was about equal to the amount of DOCA contained in $100 \mathrm{ml}$ of the rabbit serum. Nevertheless, it should be taken into account that free or conjugated form might occur, and that neither IVp represented testosterone nor Vp did DOCA. However, it would be conjectured that, in all probability, steroids, though in certain small amounts, were included in Cohn's IV-1 fraction.

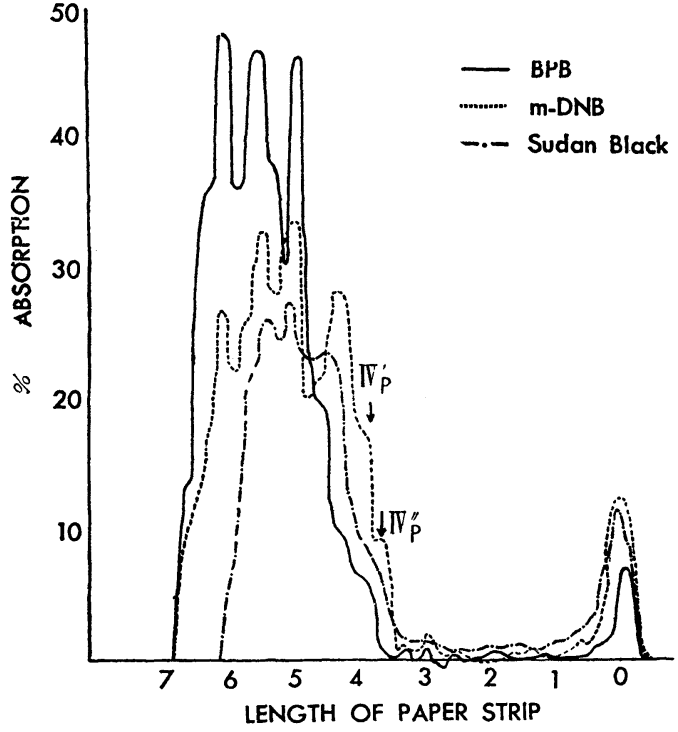

Fig. 4. Result of Paper Electrophoresis of Rabbit Sample Injected Crystallized Testosterone (60 Mins. after the Injection) 
Experiment (3) sample 3. (Fig. 3): As the result of P.E., with development with $\mathrm{BPB}$, the sample taken at 60 mins. after the injection showed no maked difference as compared with the control, but in the sample of 120 mins. the $\mathrm{A} / \mathrm{G}$ ratio was 49.0 to 50.1 . The peak of antibody themselves disappeared (Schlyer, 1954). According to tinctorial reaction to $\mathrm{m}-\mathrm{DNB}$, absorbance of Ip was measured as $33 \mathrm{~A} \%$, being due to the increase of albumin, IVp $22 \mathrm{~A} \%$ and Vp $11.4 \mathrm{~A} \%$. IVp was 1.8 times higher than the control and $\mathrm{Vp} 3.5$ times higher. Especially on just the negative side of IVp, values as high as $10 \mathrm{~A} \%$ was obtained ( $\left.\mathrm{IV}^{\prime} \mathrm{p}\right)$. According to the staining with Sudan Black, any spot was detectable on the part of albumin, regardless of the increase of the substance in the sample.

Experiment (4) sample 4. (Fig. 4): To examine in detail the steroid stained

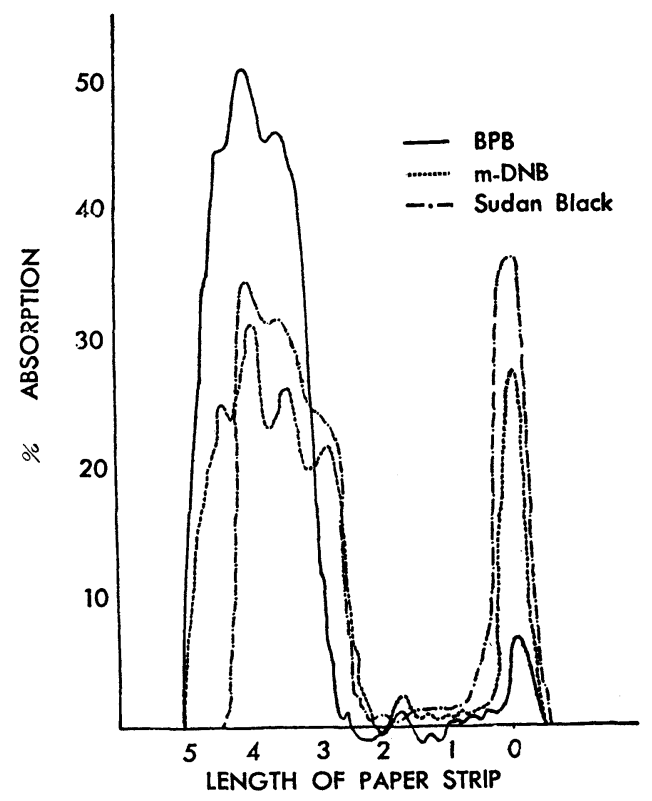

Fig. 5. Result of Paper Electrophoresis of Rabbit Sample Injected Crystallized DOCA (60 Mins. after the Injection) on IVp and Vp, observation was made on the result of intravenous injection of crystallized testosterone to the rabbit. By staining with BPB, the sample at 30 mins. after the injection was almost comparable to the control, but at the end of 60 mins. the $A / G$ ratio was 27.1 to 72.0 ,

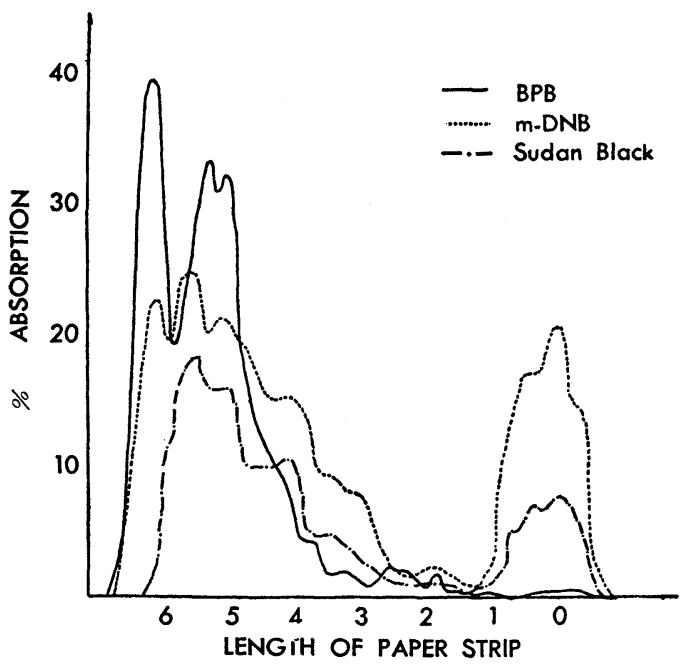

Fig. 6. Result of Paper Electrophoresis of Rabbit Sample Injected ACTH (60 Mins. after the Injection) and on the original line the substance of $7.8 \mathrm{~A} \%$ level was detected. In staining with $\mathrm{m}-\mathrm{DNB}$, at 30 mins. later each peak showed the level equal to that of the control, but at the end of 60 mins. IVp level occured as a significant peak of $28.5 \mathrm{~A} \%$, being twice as high as that of the control. According to the reaction to phosphoric acid, yellowish white fluorescence emitted by the part of IVp was looked like much intense than that in the control by naked eyes. Also, $\mathrm{Vp}$ level was $12.5 \mathrm{~A} \%$, being 4 times higher than the control level, and on the adjacent negative side of IVp, IV'p and IV'p were $16 \mathrm{~A} \%$ and $8 \mathrm{~A} \%$ respectively. 
Experiment (5) sample 5. (Fig. 5): Vp level reacted with m-DNB reagent was $11.4 \mathrm{~A} \%$ in experiment (3) and was $12.5 \mathrm{~A} \%$ in experiment (4), but in this investigation, in which free DOCA was intravenously injected into the rabbit, Vp level was observed being remarkably elevated. Result of each staining reaction showed no significant variation as compared with the control at the end of 30 mins. after the injection. In the staining with $\mathrm{BPB}$, at 60 mins. later the $\mathrm{A} / \mathrm{G}$ ratio was 24.0 to 75.9 , being approximating the value in the control. In the reaction with $\mathrm{m}$ DNB, Ip, IIp, IIIp and IVp were slightly higher than them in the control and IV'p disappeared, the level of $\mathrm{Vp}$ being $27.6 \mathrm{~A} \%$, showing marked elevation about 9 times higher as compared with the control. In the fluorescence reaction optically light pink color was emitted in the part of $\mathrm{Vp}$. In the staining with Sudan Black, absorbancy rate with 10 times higher value than the control resulted in the part corresponding to $\mathrm{Vp}$. At the end of $3 \mathrm{hrs}$. after the injection each level returned to approximately normal. Such observations are similar to those made by Nelson et al. (1952), who employing the technic developed by Porter and Silber (1950), had shown that, after intramuscular injection of comp. $F$ into healthy man, a maximum of steroid concentration on the blood had been attained at the end of $1 \mathrm{hr}$., and rapid fall of the steroid titer had ensued thereafter. But in their data steroid concentration in blood had returned to normal at the end of $8 \mathrm{hrs}$.

Experiment (6) sample 6. (Fig. 6): In the investigation made at 30 mins. after the injection of ACTH, the $\mathrm{A} / \mathrm{G}$ ratio was 36.4 to 63.3 and at 60 mins. later, 36.8 to 63.0 , in the staining reaction with BPB. Supposedly this fact might be originated in the change of protein metabolism influenced by the injection of ACTH in such a manner as Sandrucci (1953) has made inference. More or less remarkable flow of substance stained with BPB observed in the present case, which covered considerable distance toward negative side of the $\beta$-globulin part on the paper. To determine whether this substance has originated either, in one part of $\beta$-globulin or in free ACTH itself, the author treated two paper strips spotted with sample 2 or sample 2 mixed with 2 i. u. of free ACTH under the same electrophoretic condition. As the result, all free ACTH appeared on the part covering slight distance toward electro-positive side from the original line, but never moved to the part corresponding to that mentioned above. It is to be stated that, attempts with lower concentrations of the sample 6 , such flowing phenomenon was not observable. Accordingly, the flowing substance in question might deduced to be a portion of $\beta$-globulin. And a small peak of free ACTH itself employed in this experiment appeared $7 \mathrm{~A} \%$ at 30 mins. and $1.5 \mathrm{~A} \%$ at 60 mins. after the injection. In the reaction with $\mathrm{m}-\mathrm{DNB}$, in the peak of 30 mins. later Ip was a little higher and II, IIIp and IVp were at nearly the same level as compared with the control. The absorbance of $\mathrm{Vp}$ was learned to be a little more than 8 times higher level as compared with the control one, and the area of Vp reacting with m-DNB indicated over 10 times larger than the control and twice than experiment 5. This peak also fitted contour of bell-shaped curve. At the level of 60 mins. later, Ip, IIp and IIIp showed to quantitative variation as compared with the control. The level of $\mathrm{Vp}$ was 4 times higher and also on the area over 7 times larger than the control, but reduced by half as compared with the level indicated 
at 30 mins. later.

Experiment (7) sample 7: Free testosterone has a little mobility to positive side from the original line, but did not move to the part of IVp in phosphate buffer ( $\mathrm{pH} 8.0)$.

Experiment (8) sample 8: Free DOCA did not move in any detectable degree, and fluoresced light pink in reponse to antimony trichloride applied on the original line.

As the result of P.E., using free steroid mixed with albumin as material, two spots fluoresced on the paper strips; one appearing on a part of the relatively distant positive side from the original line was albumin fluorescing white blue in response to antimony trichloride and yellowish white in response to phosphoric acid, and another appearing on the original line or a part of the near positive side employed in this investigation were described in Table 1. As a rule, free steroids did not move in phosphate buffer $(\mathrm{pH} 8.0)$ and mobilities of steroids used in the experiment were higher to lower in the order of testosterone, progesterone, estradiol and ethinyl estradiol, and cortisone, hydrocortisone and dehydroisoandrosterone did not move at all. That the level of IVp elevated in experiments (4) and (3), Vp also elevated in experiments (5), (6) and (3), and IVp and Vp fluoresced characteristically with phosphoric acid and antimony trichloride, would indicate that IVp seemed to be originated in androgenic hormone and $\mathrm{Vp}$ in corticoid hormone. If the steroid contained in IV-1 fraction of each sample at the free state, on P.E. of the insoluble substance with organic solvent IVp and $\mathrm{Vp}$ were not to be detected by reaction of m-DNB. In sample 2, however, IVp decreased by about $2.6 \mathrm{~A} \%$ and $\mathrm{Vp}$ only by $1.0 \mathrm{~A} \%$.

Table 1. Fluorescence of free steroids on paper strips after paper electrophoresis with phosphoric acid and antimony trichloride

\begin{tabular}{lll}
\hline \hline \multicolumn{1}{c}{ free steroid } & $\mathrm{H}_{3} \mathrm{PO}_{4}$ & $\mathrm{SbCl}_{3}$ \\
\hline ethinyl estradiol & orange brown & orange red \\
estriol & light gray & white yellow \\
estrone & violet green & orange yellow \\
progesterone & light yellow & white yellow \\
testosterone & light yellow & yellow green \\
dehydroisoandrosterone & white yellow & reddish black \\
cortisone & light yellow & brown red \\
hydrocortisone & blue violet & brown red \\
\hline
\end{tabular}

As the result of sample 2, 4 and 5 developed with paper chromatography using non-polar solvent, it was possible to separate both of the proteins remaining at the original line and steroids having variable $\mathrm{Rf}$ values. Therefore, according to the above-stated facts, it is recognizable that each steroid representing the curves IVp and $\mathrm{Vp}$ has reacted with $\mathrm{m}-\mathrm{DNB}$ reagent in free conditions on paper strips, in consequence of which the intermolecular bond between steroids and $\alpha$-globulin or $\beta$-globulin in each sample was dissociated in electrophoretic analysis. And, in all probability, free steroids are considered to be without any concern in the above experiments. 


\section{SUMMARY}

1. Present study disclosed that relatively small amount of steroids are contained in the fraction of Cohn IV-1.

2. Steroids examined were of conjugated form with $\alpha$-globulin or $\beta$-globulin, not being in free forms.

3. Such bound steroids were dissociated from the serum protein in the treatment with P.E. and isolated steroid moved to parts of IVp and Vp, which were characteristic of m-dinitrobenzene treatment, which disappeared in BPB staining, determined by Coleman's nepho-colorimeter after color development with m-DNB.

4. IVp and $\mathrm{Vp}$ represented the curves originated in androgenic steroid hormones and corticoid hormones respectively.

The author is grateful to Prof. Y. Ito and As. Prof. H. Takikawa for their advice and helpful revisions.

\section{REFERENCES}

Barton, G. M., R. S. Evans and T. A. F. Gardner (1952.) Nature, 170, 249.

Burton, R. B., A. Zaffaroni and E. H. Keutmann (1951). J. Biol. Chem. 188, 763.

Bush, I. E. (1950). Nature, 166, 445.

Bush, I. E. (1952). Biochem. J. 50, 370.

Cohn, E. J., L. F. Strong, W. L. Hughes, D. J. Mulford, J. N. Ashworth, M. Melin and H. L.

Tayler (1946). J. Amer. Chem. Soc. 68, 459.

Dangerfield, W. G. and E. B. Smith (1955). J. Clin. Path. 8, 132.

Durrum, E. L. (1950). J. Amer. Chem. Soc. 72, 2943.

Eik-Nes, K., J. A. Schellman, R. Lumry and L. T. Samuels (1954). J. Biol. Chem. 206, 411.

Grasman, W., K. Hanning und M. Knedel (1951). Dtsh. Med. Wschr. 76, 333.

Griffiths, L. L. and D. P. H. Kent (1953). J. Lab. Clin. Med. 41, 188.

Heard, R. D. H., H. Sobel and E. H. Venning (1946). J. Biol. Chem. 165, 699.

Hemphill, R. E. and M. Reiss (1947). Endocrinol. 41, 17.

Isobe, S. (1955). Annual Reports of Junior College of Takasaki, 3. (In Japanese)

McKineley W.P. (1955). Science, 121, 139.

Neher R. und A. Wettstein (1951). Helv. Chim. Acta. 34, 2053.

Neher R. und A. Wettstein (1951). Helv. Chim. Acta. 34, 2278.

Nelson D.H., A.A. Sandberf, J.G. Palmer and F.H. Tyler (1952). J. Clin. Invest. 31, 843.

Porter G.C. and R.H. Silber (1950). J. Biol. Chem. 185, 201.

Sandrucci M.G. (1963). Minerva Pediatrica, 30, 283.

Schleyer (1954). Klin. Wschr. 32, 730.

Voigt K.D. und I. Beckmann (1953). Acta Endocrinol. 13, 19.

Voigt K.D. und I. Beckmann (1954). Acta Endocrinol. 15, 251.

Zaffaroni A., R.B. Burton and F.H. Keutmann (1950). Science, 111, 6.

Zaffaroni A. and R.B. Burton (1951). J. Biol. Chem. 193, 769. 